\title{
Determinants of consumption-based carbon emissions in Chile: an application of non-linear ARDL
}

\author{
Tomiwa Sunday Adebayo $^{1}$ (D) $\cdot$ Edmund Ntom Udemba $^{2}$ (D) Zahoor Ahmed $^{3}$ (D) $\cdot$ Dervis Kirikkaleli $^{4}$ (D)
}

Received: 27 January 2021 / Accepted: 5 April 2021 / Published online: 11 April 2021

(C) The Author(s), under exclusive licence to Springer-Verlag GmbH Germany, part of Springer Nature 2021

\begin{abstract}
In recent years, a growing number of scholars have employed various proxies of environmental degradation to understand the reasons behind rising environmental degradation. However, very few studies have considered consumption-based carbon emissions, even though a clear understanding of the impact of consumption patterns is essential for redirecting the pattern to more sustainable consumption. Thus, this study takes a step forward by using consumption-based carbon emissions $\left(\mathrm{CCO}_{2}\right)$ as a proxy of environmental degradation using the novel non-linear ARDL technique for Chilefrom 1990 to 2018. To the best understanding of the investigators, no prior studies have investigated the drivers of consumption-based carbon emissions utilizing non-linear ARDL. The study employed ADF and KSS (non-linear) tests to check the data series' stationary level. Additionally, the symmetric and asymmetric ARDL approaches are utilized to explore cointegration and long-run linkages. According to the results, there is no symmetric cointegration among the variables; however, the empirical estimates reveal a long-run asymmetric connection between the indicators and $\mathrm{CCO}_{2}$ emissions. The novel results from the asymmetric ARDL indicate that negative and positive changes in economic growth deteriorate the quality of the environment. Interestingly, a reduction in economic growth makes a more dominant contribution to environmental degradation. Moreover, positive changes in renewable energy usage improve the quality of Chile's environment, inferring that the country can achieve a reduction in environmental degradation by boosting renewable energy consumption. Surprisingly, the study found that technological innovation is ineffective in reducing consumption-based carbon emissions, which implies that Chile's technological innovation is not directed towards manufacturing green technology. Finally, the policy implications are discussed with respect to reducing consumption-based carbon emissions.
\end{abstract}

Keywords Consumption-based carbon emissions $\cdot$ Economic growth $\cdot$ Renewable energy consumption $\cdot$ Technological innovation $\cdot$ NARDL

\section{Introduction}

Climate change is a worldwide concern that requires even more focus than Covid-19. This impacts the whole Earth

\begin{tabular}{l}
\hline Responsible Editor: Ilhan Ozturk \\
\hline $\begin{array}{l}\text { Tomiwa Sunday Adebayo } \\
\text { twaikline@gmail.com }\end{array}$ \\
$\begin{array}{l}\text { Edmund Ntom Udemba } \\
\text { eudemba@gelisim.edu.tr }\end{array}$ \\
Zahoor Ahmed \\
zahoorahmed83@yahoo.com \\
Dervis Kirikkaleli \\
dkirikkaleli@eul.edu.tr
\end{tabular}

negatively with multifaceted problems such as global warming, melting of Antarctica and rising sea levels, reduction in the availability of water and upsurge in disease, and the extinction of wild and aquatic creatures (Akinsola and

1 Faculty of Economics and Administrative Science, Department of Business Administration, Cyprus International University, Nicosia, Northern Cyprus, TR-10 Mersin, Turkey

2 Faculty of Economics Administrative and Social sciences, Istanbul Gelisim University, Istanbul, Turkey

3 School of Management and Economics, Beijing Institute of Technology, Beijing 100081, China

4 Faculty of Economic and Administrative Sciences, Department of Banking and Finance, European University of Lefke, Lefke, Northern Cyprus, TR-10 Mersin, Turkey 
Adebayo 2021; Wang et al. 2021b). In a bid to curtail the increase in climate change and global warming, the United Nations Framework Convention on Climate Change (UNFCCC) held a meeting in Paris in 2015. The Paris Agreement, advocates for the commitment of both developed and developing countries to maintaining a temperature level under or marginally above the preindustrial level. Following the ratification of the Paris Agreement by many countries, including Chile, which is premised on maintaining the temperature level of $2{ }^{\circ} \mathrm{C}$ above preindustrial level and $1.5^{\circ} \mathrm{C}$, the individual countries (developed and developing) need to work towards the stipulated target (Umar et al. 2020; Alola and Kirikkaleli 2020; Adebayo and Kirikkaleli 2021).

One of the Paris Agreement targets, as specified under Articles 2 and 7, is to encourage the capacity to adapt to the negative impacts of climate change, boost climate resilience, and lower the level of greenhouse gas (GHG) emissions. In this regard, Chile is one of the countries identified as being a signatory of the Paris Agreement. The country has adopted various policies in order to achieve this target, such as actions aimed at protecting people and their rights, livelihoods, and ecosystems. The steps include the urgent and immediate need to identify the causes of emissions in each sector at the national and subnational scale. Consumption patterns represent one of the drivers causing the increase in emissions. This is classified as consumption-based emissions. Sustainable consumption with sustainable production styles is part of the roadmap towards the achievement of the 2030 global goals for sustainable development as enshrined in the Sustainable Development Goal (SDG) 12. A clear understanding of the impact of consumption patterns on emissions will help redirect the pattern to more sustainable consumption. Mitigating climate change requires the identification of causes and ways of alleviating them, and one of the causes of climate change is the production of carbon emissions from different sources. Economic activities targeting growth and development, such as manufacturing involving the production and consumption of products, constitute one of the causes of climate change. The transition from the agricultural age to the industrialization age has paved the way for excessive utilization of fossil fuels, which lead to the pollution of earth bodies (air, land, and water bodies) that constitute the environment.

The economic activities that give rise to emissions can be viewed from the angles of consumption and production. Production-based emissions include all carbon footprints from the production of goods and services domestically and overseas, while consumption-based emissions are caused by the country's final demand for goods and services that are largely produced abroad. While the production-based carbon emissions have been intensively researched, this has been criticized due to the lack of focus on carbon leakage issues in trade liberalization (Peters and Hertwich 2008; Munksgaard et al. 2005; Su and Ang 2014). Direct emission levels and emission patterns from production activities have been the focus of research in terms of the effects of climate policy and mitigation initiatives. However, more scholars have proposed a different perspective with a direct and more reasonable means of measuring emissions from end users, defined as consumptionbased carbon emissions (Barrett et al. 2013; Ferng 2003; Feng et al. 2013; Brizga et al. 2017). A general rise in income mostly triggers an increase in consumption, and this is considered as one of the greatest drivers of resource-use and environmental degradation globally.

Global economic activities are significantly driving consumption, and this will provide an insight into the role of consumption in driving global emissions. Consumer behavior and lifestyles have a major impact on energy use and trigger emissions. An increasing proportion of world greenhouse gas (GHG) emissions emanating from production can be linked to consumer behaviors and patterns. Various different studies have been based on different indices such as economic growth, agriculture, non-renewables, trade, and foreign direct investment, with regard to their capacity to induce climate change via carbon emissions with minimal attention on consumption-based carbon emission. Trade openness with regard to the flow of goods and services and increased economic activities have been identified as being important factors that explain carbon emissions (Liu et al. 2015). The benefit of this accounting perspective is the accurateness of measuring emissions without double counting. This is possible by ensuring that emissions from goods and services produced for exports are excluded and counted at the end-user's point. Among the benefits of consumption, carbon accounting includes sustainable consumption together with sustainable production, which is in line with SDG 12, and assists a country with respect to its national commitment in curtailing emissions at the national level, thereby conforming to the requirements of the UNFCC Paris Agreement.

International trade degrades the environment through carbon leakage by shifting carbon emission-intensive industries to other economies. In their efforts to reduce the impacts of emissions on climate change, countries around the world have implemented different measures to mitigate carbon emissions, such as technological innovation and the adoption of renewable energy sources. Technological innovation can be achieved in various ways, but research and development (R\&D) has been identified as an efficient way of reducing emissions (Zhang et al. 2017). The effectiveness of technological innovation towards curbing emission has been researched by various scholars (Lee and Min 2015; Zhang and Da 2015; Cai and Zhou 2014). An aspect of technological innovation is storage technology and carbon capture, which can control $\mathrm{CO}_{2}$ emissions (Huaman and Tian 2014). Among the initiatives that have gained global acceptance in pollution control is the adoption of renewable sources of energy (Chiu and Chang 2009; Gessinger 1997) in the execution of economic and production activities. 
No study has explored the drivers of $\mathrm{CCO}_{2}$ emissions in Chile. Also, in the previous literature, most studies have adopted linear techniques to study the factors causing the increase in $\mathrm{CCO}_{2}$ emissions. On this note, this study aims to investigate the determinants and possible ways of mitigating consumption-based-carbon emission for the case of Chile. Consumption-based carbon emissions play a direct and relevant role in climate policies. As previously noted, Chile has been ranked as one of the most committed countries in terms of controlling its national emissions to reduce the impact of climate change. It has introduced various strategies to reduce fossil fuel consumption and augment renewable energy consumption, and this makes the country a good example for understanding its effort to mitigate $\mathrm{CCO}_{2}$. Chile is projected to exceed its 2020 pledge with some of its policies, including the adoption of the carbon tax and unconventional renewable energy laws aimed at achieving its carbon neutrality and energy transition targets, and the strategy to divert electricity production from coal-based electricity supply to other sources by retiring its eight coal-fired power plants (Carbon Action Tracker, 2020). Also, the willingness of Chile to move away from fossil fuels can be understood from its adoption of the electro-mobility strategy, which is targeted at achieving electrification of 40 and $100 \%$ of the private and public transport in cities by 2050, respectively (Carbon Action Tracker, 2020). Moreover, it is anticipated that COVID-19 will make a positive contribution to reducing the intensity of greenhouse gas emissions of the economy in 2020 and 2021. This contributes to the projections that Chile is one of the few countries that is likely to meet its emission reduction targets. In the process of moving towards carbon neutrality by shifting to renewable energy sources, Chile intends to completely phase out coal plants by 2040 (Carbon Action Tracker, 2020). To do justice to this topic, we incorporate factors (renewable energy, technological innovation) that are capable of controlling and mitigating emissions in our empirical estimation and analysis. Although this is not the first work to assess climate change with the identified variables, the novelty and uniqueness of our study are based on the fact that it deviates from the popular method using production-based carbon emissions to the adoption of consumption-based carbon emission accounting. The adoption of recent approaches, namely symmetric (linear) and asymmetric (non-linear) ARDL incorporating structural breaks in the analysis, also distinguishes this study from others. The asymmetric ARDL method will allow us to decompose regressors into their positive and negative changes; hence, in addition to linear effects, the study will reveal how positive and negative shocks in the regressors impact $\mathrm{CCO}_{2}$.

The remaining part of the research is structured as follows: a review of past studies is depicted in "Literature review" section, and the methodology is illustrated in "Methodology" section. "Discussion of findings" section entails the findings and discussion. Lastly, "Conclusion and policy direction" section presents the study conclusion and policy path.

\section{Literature review}

Literature has shown and proved that fossil fuel energy contributes to carbon emissions (Kirikkaleli and Adebayo 2021; Oluwajana et al. 2021; Udemba 2019, 2020a, b, c, 2021; Apergis and Ozturk 2015; Stern 2016 Ahmed et al. 2020c; Adebayo 2021). In a bid to curb the carbon emissions from fossil fuels, renewables such as wind, solar, hydro, and geothermal have been identified as potential ways of substituting fossil fuels, thus reducing the excessive emissions (Chiu et al. 2009; Ahmed and Le 2021). These variables have been considered at country, regional, and cross-sectional levels to explore their climate change involvement (Ahmed et al. 2020a, b). Zhang and Da, 2015; Liu et al. 2015; Yu et al. 2012; Mi et al. 2015; Adebayo and Kirikkaleli 2021). Changing focus to the investigation of the role of increasing consumption in inducing carbon emissions (consumption-based carbon emissions $\left(\mathrm{CCO}_{2}\right)$ accounting $)$ is a new idea capable of providing the research world with new insights into efforts to mitigate climate change. From the consumption-based carbon emissions perspective, products and services purchased by people are measured. Also, emissions are distributed to the consumers of goods and services (Dawkins et al. 2010; Afionis et al. 2017).

Some studies have investigated the aforementioned factors with mixed findings. The study of Hasanov et al. (2018) found that imports and exports increase and decrease emissions, respectively. The impact of imports and consumption on $\mathrm{CO}_{2}$ emissions was investigated by Sheau-Ting and Al-Mulali (2014) for six regions and the study found that imports increase emissions. Renewable and non-renewable energies were considered in the carbon emissions study of SubSahara African countries by Inglesi-Lotz and Dogan (2018), who found that renewable energy controls carbon emissions.

Likewise, Mensah et al. (2018) and Bhattacharya et al. (2016) established that technological innovation and renewable energy control carbon emissions. Shahbaz et al. (2018) studied financial development and energy innovation in France. The study found that both energy innovation and financial development reduce carbon emissions. ÁlvarezHerránz et al. (2017) researched OECD countries with regard to energy innovation and found that energy innovation controls emission. Furthermore, other studies such as Bhattacharya et al. (2020); Khan et al. (2020a); Khan et al. (2020b); Knight and Schor (2014); He et al. (2021); Kirikkaleli and Adebayo (2021); and Khan et al. (2020c) studied and calculated environmental performance with consumption-based measures. Bhattacharya et al. (2020) examined the convergence of consumption-based and territory- 
based carbon emissions intensity across 70 countries. They found two convergent clubs for consumption-based emissions and three convergent clubs for territory-based emissions. They also found that increases in total factor productivity, renewable energy consumption, and urbanization increase the odds of belonging to a low carbon emissions intensity club. Khan et al. (2020a, b, c) confirmed the negative effect of exports on consumption-based carbon emissions in both the short run and long run.

Khan et al. (2020b) found that imports and income enhance consumption-based carbon emissions in the long run, while exports, environmental innovation, and renewable energy consumption mitigate consumption-based $\mathrm{CO}_{2}$ emissions. Knight and Schor (2014) found that economic growth exert positive impact on consumption-based emissions and not territorial emissions. He et al. (2021) confirmed that financial development, energy usage, and economic growth can predict consumption-based carbon emissions at different frequencies. In contrast, trade openness and globalization can predict significant variations in consumption-based carbon emissions. Kirikkaleli and Adebayo (2021) confirmed a long-run cointegration between consumption-based carbon dioxide emissions and their possible determinants. Khan et al. (2020c) found a negative effect of exports on consumption-based carbon emissions. For this discussion, it is evident that the determinants of $\mathrm{CCO}_{2}$ are yet to be explored in the context of Chile. In addition, previous studies have adopted linear techniques in probing the factors influencing $\mathrm{CCO}_{2}$ emissions.

\section{Methodology}

\section{Descriptions of data and theoretical foundation}

The present research explores the impact of economic growth (GDP), renewable energy consumption (REN), and technological innovation (TI) on consumption-based carbon emissions $\left(\mathrm{CCO}_{2}\right)$ in Chile using yearly data stretching between 1990 and 2018. The variables utilized are transformed into their natural logarithm. This was conducted to ensure that data is normally distributed (Kirikkaleli et al. 2020; Balsalobre-Lorente and Leitão 2020). Table 1 shows the data source, measurement, and unit of measurement. Also, the flow of analysis is illustrated in Fig. 1. The study economic function is depicted in Eq. 1:

$\mathrm{CCO}_{2 t}=f\left(\mathrm{GDP}_{t}, \mathrm{REN}_{t}, \mathrm{TI}_{t}\right)$

In Eq. 1, GDP, REN, TI, and $\mathrm{CCO}_{2}$ represent economic growth, renewable energy, technological innovation, and consumption-based carbon emissions, respectively. Therefore, the economic model of the current research is presented in Eq. 2;
Table 1 Variables units and sources

\begin{tabular}{|c|c|c|c|}
\hline Variable & Description & Units & Sources \\
\hline $\mathrm{CCO}_{2}$ & $\begin{array}{r}\text { Consumption-based } \\
\text { carbon emissions }\end{array}$ & $\begin{array}{l}\text { Million tons of } \mathrm{CO}_{2} \\
\text { emissions }\end{array}$ & $\begin{array}{c}\text { GCA by Peters } \\
\text { et al. (2011) } \\
\text { and Gilfillan } \\
\text { et al. (2019) }\end{array}$ \\
\hline GDP & Economic growth & $\begin{array}{l}\text { GDP per capita } \\
\text { constant } \$ \text { US } \\
2010\end{array}$ & WDI (2020) \\
\hline TI & $\begin{array}{l}\text { Technological } \\
\text { innovation }\end{array}$ & $\begin{array}{l}\text { Measured as the } \\
\text { addition of patent } \\
\text { applications, } \\
\text { residents and } \\
\text { patent } \\
\text { applications, } \\
\text { non-residents }\end{array}$ & \\
\hline REN & Renewable energy & $\begin{array}{r}\text { Renewables per } \\
\text { capita }(\mathrm{kWh})\end{array}$ & BP (2020) \\
\hline
\end{tabular}

Source: Authors compilation

$\mathrm{CCO}_{2 t}=\vartheta_{0}+\vartheta_{1} \mathrm{GDP}_{t}+\vartheta_{2} \mathrm{REN}_{t}+\vartheta_{3} \mathrm{TI}_{t}+\varepsilon_{t}$

The reasons why the aforementioned parameters are incorporated are discussed here. In the past two decades, numerous scholars (Kirikkaleli et al. 2020; Ahmed et al. 2020a, b; Alola et al. 2020; Shahbaz et al. 2020) have explored these interconnections. Nevertheless, prior studies did not incorporate $\mathrm{CCO}_{2}$ emissions as a proxy of environmental degradation. Instead, they used $\mathrm{CO}_{2}$ emissions and ecological footprint, etc., as proxies of environmental degradation. The uniqueness of using $\mathrm{CCO}_{2}$ carbon emissions is that it takes into account the global supply chain that contributes to the creation of emissions and distinguishes between emissions created in one nation and used in another (Safi et al. 2020; Khan et al. 2020a, b, c; Knight and Schor, 2014; Shahbaz et al. 2020).

Following the studies of Balsalobre-Lorente and Leitão (2020), Odugbesan and Adebayo (2020a, b), Magazzino et al. (2020), Ayobamiji and Kalmaz (2020), Kirikkaleli and Adebayo (2020), and Zhang et al. (2021), the present research incorporates GDP into the model. The interrelationship between environmental pollutions and economic growth is projected to be positive. This denotes that an increase in economic growth would increase environmental degradation, i.e., $\left(\beta_{1}=\frac{\partial \mathrm{CCO}_{2}}{\partial \mathrm{GDP}}>0\right)$. Also, following the studies of Alola (2019), Shahbaz et al. (2020), and Kirikkaleli and Adebayo (2020), the current study introduces renewable energy usage into the framework. The association between renewable energy usage and environmental pollutions is expected to be negative. This infers that an increase in renewable energy usage would enhance environmental quality, i.e., $\left(\beta_{2}=\frac{\partial \mathrm{CCO}_{2}}{\partial \mathrm{REN}}<0\right)$ . The study also investigates the linkage between innovation and environmental pollution. In line with prior studies (Khan 
Fig. 1 Flow chart

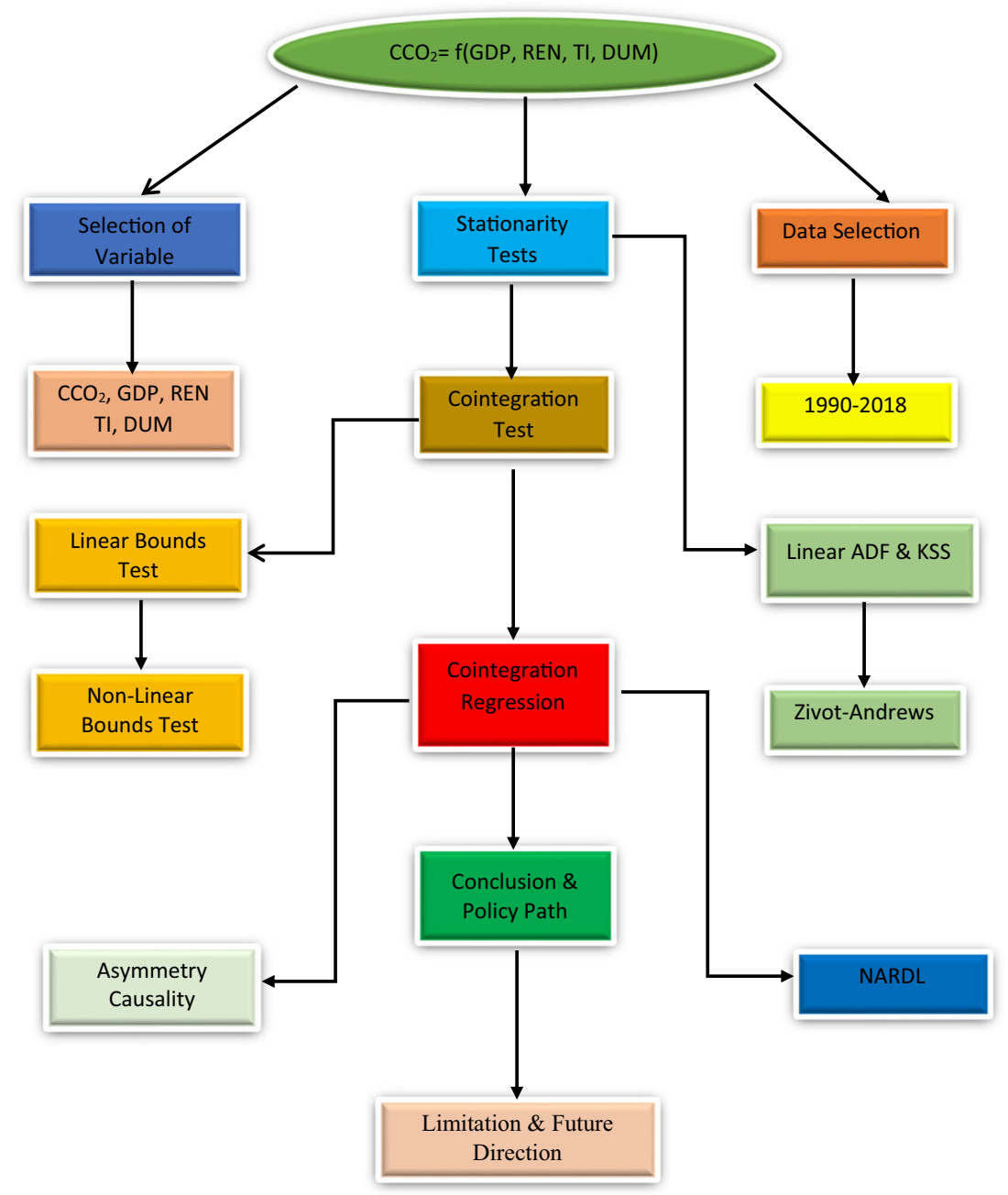

et al. 2020; Kirikkaleli and Adebayo, 2020; Shahbaz et al. 2020), technological innovation is incorporated into the model. Thus, the association between technological innovation and environmental degradation is expected to be negative if the technology is eco-friendly, i.e., $\left(\beta_{3}=\frac{\partial \mathrm{CCO}_{2}}{\partial \mathrm{TI}}<0\right)$, otherwise $\left(\beta_{3}=\frac{\partial \mathrm{CCO}_{2}}{\partial \mathrm{TI}}>0\right)$ if it is not eco-friendly.

To ascertain asymmetric effects, renewable energy usage, economic growth, and technological innovation are disintegrated into positive and negative changes $\left(\mathrm{GDP}^{+}\right.$, $\mathrm{GDP}^{-}, \mathrm{REN}^{+}, \mathrm{REN}^{-}, \mathrm{TI}^{+}, \mathrm{TI}^{-}$). Ahmed et al. (2021) suggested that fiscal and monetary policies, international trade, phases of business cycles, etc., can influence macroeconomic variables leading to asymmetric properties; hence, we divide regressors into positive and negative changes since their effect may vary in direction and magnitude. Equation 2 (econometric model I) is transformed into Eq. 3 as follows:

$$
\begin{aligned}
\mathrm{CCO}_{2 t}= & \vartheta_{0}+\vartheta_{1} \mathrm{GDP}_{t}^{+}+\vartheta_{2} \mathrm{GDP}_{t}^{-}+\vartheta_{3} \mathrm{REN}_{\mathrm{t}}^{+} \\
& +\vartheta_{4} \mathrm{REN}_{t}^{-}+\vartheta_{5} \mathrm{TI}_{t}^{+}+\vartheta_{6} \mathrm{TI}_{t}^{-}+\varepsilon_{t}
\end{aligned}
$$

\section{Econometric method}

\section{Unit root test}

This study's econometric approach comprised the usage of nonlinear approaches to investigate long-term impacts and causal relations. Before implementing non-linear ARDL (NARDL), it is essential to investigate non-linear parameters. Therefore, the research utilized the renowned BDS test. This test is utilized to affirm whether the linear or non-linear modeling is suitable for the study. Several recent studies such as Odugbesan and Adebayo (2020), Ahmed et al. (2020a, b, c), and Sheikh et al. (2020) utilized the BDS test developed by Brock et al. (1996). The null and alternative hypotheses of the BDS test are linearly dependence and non-linearly dependence. Furthermore, the rejection of the null hypothesis denotes the existence of nonlinearities and the suitability of the non-linear modeling. After the pre-requisite is satisfied, the current study chooses a unit-root test utilizing the ADF and KSS (non-linear) tests. It should be remembered that the use of this test is merely to capture the stationarity features of series, as the prior tests may yield results 
that are misleading if there is evidence of a break(s) in the series. Although NARDL can house fractional integration, the nonlinear or linear ARDL may not be reliable if there is no evidence of a unit root in the dependent variable; therefore, it is reasonable to utilize a unit root test that can capture both structural break(s) and the stationarity features of the series. Accordingly, the current study employed the Zivot and Andrews (ZA) test developed by Zivot and Andrews (2002).

\section{RDL approach (linear and non-linear)}

The current study utilized linear (symmetric) and non-linear (asymmetric) ARDL techniques. The symmetric and asymmetric ARDL methods are versatile and can be extended to parameters integrated at order 1(0) or 1 (1). Applying the ARDL involves the selection of and adequate lag, and the potential issue of endogeneity can be resolved by selecting an appropriate lag length. Shin et al. (2014) stated that a sufficient lag length is also effective in addressing the problem of potential multicollinearity in the NARDL. The ARDL method produces both long-run and short-run outcomes. Equation 1 is transformed into the following symmetric ARDL framework. Shin et al. (2014) stated that the optimal lag period is also useful in resolving potential multicollinearity problems in the asymmetrical ARDL. The ARDL method produces short-term and long-term results as a whole, and the lagged ECT reveals details on convergence. The symmetrical ARDL model is depicted in Eq. 1 as follows.

$$
\begin{aligned}
\Delta \mathrm{CCO}_{2 t}= & \vartheta_{0}+\sum_{i=1}^{t} \vartheta_{1} \Delta \mathrm{CCO}_{2 t-i}+\sum_{i=1}^{t} \vartheta_{2} \Delta \mathrm{GDP}_{t-i} \\
& +\sum_{i=1}^{t} \vartheta_{3} \Delta \mathrm{REN}+\sum_{i=1}^{t} \vartheta_{4} \Delta \mathrm{TI}_{t-i} \\
& +\sum_{i=1}^{t} \vartheta_{5} \Delta \mathrm{DUM}_{t-i}+\beta_{1} \mathrm{CCO}_{2 t-1} \\
& +\beta_{2} \mathrm{GDP}_{t-1}+\beta_{3} \mathrm{REN}_{t-1}+\beta_{4} \mathrm{TI}_{t-1} \\
& +\beta_{5} \mathrm{DUM}_{t-1}+\varepsilon_{t}
\end{aligned}
$$

where the short-run coefficients are depicted by $\vartheta_{1,2,3,4,5}$ and long-run coefficients by $\beta_{1,2,3,4,5}$. Also, the first difference operator is signified by $\Delta$, and $\varepsilon_{t}$ is the error term. The null $\left(H_{0}\right)$ and the alternative $\left(H_{a}\right)$ hypothesis for the ARDL bound test are presented in Eqs. 5 and 6, respectively.

$$
\begin{aligned}
& H_{0}=\beta_{1}=\beta_{2}=\beta_{3}=\beta_{4} \\
& H_{a} \neq \beta_{1} \neq \beta_{2} \neq \beta_{3} \neq \beta_{4}
\end{aligned}
$$

To reject the null hypothesis, the $F$-stat must be greater than both the lower and upper bound critical values.

After confirming that the series is not stationary at $\mathrm{I}(2)$, the present study utilized the NARDL. This approach is beneficial for verifying the existence of non-linear cointegration between parameters. It also estimates the short-run and long-run association between the explanatory variables and the dependent variable. As Ahmed et al. (2021) stated, this approach's versatility to utilize an ideal lag length will resolve the possible issue of multicollinearity. Furthermore, it can also accommodate fractional integration and possible endogenous and autocorrelation problems (Odugbesan and Adebayo 2020a, b; Onyibor et al. 2020; Adedoyin et al. 2020). In addition to all these advantages, the ability of linear ARDL to produce reliable findings for small sample sizes renders it one of the favored options for the analysis of time-series. The NARDL decomposes parameters with their corresponding positive and negative shifts. Thus, renewable energy usage, economic growth, and technological innovation will be decomposed into negative and constructive shifts in our key model. As previously mentioned in Eq. 3, we have already illustrated parameters into corresponding shocks $\left(\mathrm{GDP}^{+}, \mathrm{GDP}^{-}, \mathrm{REN}^{+}, \mathrm{REN}^{-}, \mathrm{TI}^{+}, \mathrm{TI}^{-}\right)$. Furthermore, the partial sum of renewable energy usage shifts, economic growth, and technological innovation are as follows.

$$
\begin{aligned}
& \mathrm{GDP}^{+}=\sum_{i=1}^{t} \Delta \mathrm{GDP}^{+}+\sum_{i=1}^{t} \max \left(\mathrm{GDP}_{i}, O\right) \\
& \mathrm{GDP}^{-}=\sum_{i=1}^{t} \Delta \mathrm{GDP}^{-}+\sum_{i=1}^{t} \min \left(\mathrm{GDP}_{i}, O\right) \\
& \mathrm{REN}^{+}=\sum_{i=1}^{t} \Delta \mathrm{REN}^{+}+\sum_{i=1}^{t} \max \left(\operatorname{REN}_{i}, O\right) \\
& \mathrm{REN}^{-}=\sum_{i=1}^{t} \Delta \mathrm{REN}^{-}+\sum_{i=1}^{t} \min \left(\operatorname{REN}_{i}, O\right) \\
& \mathrm{TI}^{+}=\sum_{i=1}^{t} \Delta \mathrm{TI}^{+}+\sum_{i=1}^{t} \max \left(\mathrm{TI}_{i}, O\right) \\
& \mathrm{TI}^{-}=\sum_{i=1}^{t} \Delta \mathrm{TI}^{-}+\sum_{i=1}^{t} \min \left(\mathrm{TI}_{i}, O\right)
\end{aligned}
$$

Nonetheless, Eq. 4 mentioned earlier can be revamped into the following NARDL model, correspondingly.

$$
\begin{aligned}
\Delta \mathrm{CCO}_{2 t}= & \vartheta_{0}+\sum_{i=1}^{t} \vartheta_{1} \Delta \mathrm{CCO}_{2 t-i}+\sum_{i=1}^{t} \vartheta_{2} \Delta \mathrm{GDP}_{t-1}^{+} \\
& +\sum_{i=1}^{t} \vartheta_{3} \Delta \mathrm{GDP}_{t-1}^{-}+\sum_{i=1}^{t} \vartheta_{4} \Delta \mathrm{REN}_{t-1}^{+} \\
& +\sum_{i=1}^{t} \vartheta_{5} \Delta \mathrm{REN}_{t-1}^{-}+\sum_{i=1}^{t} \vartheta_{6} \Delta \mathrm{TI}_{t-1}^{+} \\
& +\sum_{i=1}^{t} \vartheta_{7} \Delta \mathrm{TI}_{t-1}^{-}+\sum_{i=1}^{t} \vartheta_{8} \Delta \mathrm{DUM}_{t-1} \\
& +\beta_{1} \mathrm{CCO}_{2 t-1}+\beta_{2} \mathrm{GDP}_{t-1}^{+}+\beta_{3} \mathrm{GDP}_{t-1}^{-} \\
& +\beta_{4} \mathrm{REN}_{t-1}^{+}+\beta_{5} \mathrm{REN}_{t-1}^{-}+\beta_{6} \mathrm{TI}_{t-1}^{+} \\
& +\beta_{7} \mathrm{TI}_{t-1}^{-}+\beta_{8} \mathrm{DUM}_{t-1}+\rho \mathrm{ECT}_{t-i}+\varepsilon_{t}
\end{aligned}
$$


In the NARDL, non-linear cointegration is examined using the Bounds test. To reject the null hypothesis in NARDL, the $F$-stat must be greater than both the lower and upper bound critical values. Further, the study uses various diagnostic measures to examine the stability of the asymmetrical models. In the asymmetrical ARDL method, we have utilized the WALD test to validate the long-term asymmetrical impact.

\section{Asymmetric causality}

There is always a distinction in the reaction between negative and positive shocks, which render it reasonable to apply the asymmetries causality. Consequently, in the last stage of the present research, the Hatemi-j (2012) causality is deployed. This approach utilizes the theoretical foundation of the Toda and Yamamoto approach; moreover, it has the potential to separate parameters into negative and positive shocks by introducing non-linear effects. This method separates the parameters into the corresponding shocks, then tests their causality from negative shocks to negative shocks and positive shocks to positive shocks under the VAR framework. When the modified WALD statistics is greater than the bootstrap critical values, the null hypothesis of no asymmetric causality is rejected. In this causality method, the bootstrap process is used to obtain causal results, which makes it more useful for a small sample size compared to other techniques. Using the bootstrap simulations with leverage correction, this test's critical values are generated; therefore, they are robust to both time-varying volatility and non-normality. Furthermore, asymmetric causality provides benefits, such as the ability to accommodate asymmetric structure, better power and size properties, robustness against $\mathrm{ARCH}$, and non-normality. Hence, these factors make asymmetric causality a reliable method for capturing causal interactions.

\section{Discussion of findings}

This study investigates the symmetric and asymmetric impact of technological innovation, renewable energy usage, and economic growth on consumption-based carbon emissions between 1990 and 2018 in Chile. Table 2 presents a statistical summary and the different normality tests utilized. Moreover, the parameters' mode, maximum, mean, standard deviation, minimum, and median are illustrated by the descriptive statistics. Table 2 shows that GDP has the highest mean (10890.70), which is followed by renewable energy consumption (REN) with a mean of 3973.883, and technological innovation and consumption-based carbon emissions with means of 2494.000 and 63.85005 , respectively. The research used Kurtosis to verify whether the series is light-tailed or heavytailed relative to normal distribution. The empirical outcomes
Table 2 Descriptive statistics

\begin{tabular}{lllll}
\hline & $\mathrm{CCO}_{2}$ & GDP & REN & TI \\
\hline Mean & 63.85005 & 10890.70 & 3973.883 & 2494.000 \\
Median & 60.12730 & 10726.64 & 3930.835 & 2792.000 \\
Maximum & 93.43620 & 15111.70 & 5471.402 & 3952.000 \\
Minimum & 31.13620 & 5933.207 & 2072.491 & 811.0000 \\
Std. dev. & 20.10264 & 2886.701 & 677.5301 & 853.1786 \\
Skewness & -0.029779 & -0.046307 & -0.574684 & -0.540442 \\
Kurtosis & 1.867291 & 1.744942 & 4.177907 & 2.288933 \\
Jarque-Bera & 1.554613 & 1.913696 & 3.272786 & 2.022660 \\
Probability & 0.459642 & 0.384102 & 0.194681 & 0.363735 \\
Observations & 29 & 29 & 29 & 29 \\
\hline
\end{tabular}

illustrate that all the series are Platykurtic since their values are less than 3 with the exemption of renewable energy consumption. Additionally, the parameters' skewness is less than 1, which illustrates that they are moderately skewed. Also, the outcomes from the Jarque-Bera (JB) probability show that all the parameters conform to normality.

To ascertain the parameters' linearity, the current study utilized the BDS test initiated by Broock et al. (1996) to capture non-linearity. The BDS test outcomes are depicted in Table 3, which demonstrate that the variables possess nonlinearities. Based on the non-linearity outcomes, it is necessary to utilize non-linear techniques to investigate the interconnection between technological innovation, economic growth, renewable energy, and $\mathrm{CCO}_{2}$ emissions. Accordingly, the current research utilized the non-linear ADF and KSS tests. The outcomes of the ADF and KSS tests are depicted in Table 4. The results of the non-linear ADF and KSS reveal that at level, i.e., I(0), we fail to reject the null hypothesis. However, after the first difference, i.e., I(1), is taken, the series are stationary, indicating that there is no unit root. Moreover, as stated by Olanrewaju et al. (2021), Adebayo (2020), Alola (2019), and Kirikalleli et al. (2020), the application of both ADF and KSS unit root testing approaches may yield misleading outcomes as they disregard

Table 3 BDS test to inspect non-linearity

\begin{tabular}{llllll}
\hline & $M=2$ & $M=3$ & $M=4$ & $M=5$ & $M=6$ \\
\hline$T$-Stat & BDS stat & & & & \\
$\mathrm{CCO}_{2}$ & $0.1844^{*}$ & $0.3106^{*}$ & $0.4017^{*}$ & 0.4661 & $0.5107^{*}$ \\
GDP & $0.1918^{*}$ & $0.3197 *$ & $0.4119^{*}$ & $0.4795^{*}$ & $0.5293^{*}$ \\
REN & $0.1400^{*}$ & $0.2303 *$ & $0.2891^{*}$ & $0.3141^{*}$ & $0.3306^{*}$ \\
TI & $0.1753^{*}$ & $0.2908^{*}$ & $0.3732^{*}$ & $0.4234^{*}$ & $0.4522^{*}$ \\
\hline
\end{tabular}

Note: * refers $1 \%$ level of significance. Residual values computed from the BDS test with $\mathrm{m}$ dimensions show the presence of non-linearities in variables 
Table 4 ADF and KSS tests

\begin{tabular}{|c|c|c|c|c|c|c|c|c|}
\hline \multirow[t]{3}{*}{ Variables } & \multicolumn{4}{|l|}{$\mathrm{ADF}$} & \multicolumn{4}{|l|}{ KSS } \\
\hline & \multicolumn{2}{|l|}{ Level } & \multicolumn{2}{|l|}{ Difference } & \multicolumn{2}{|l|}{ Level } & \multicolumn{2}{|l|}{ Difference } \\
\hline & $T$-Stat & $p$ value & $T$-Stat & $p$ value & KSS stat & $P$ values & KSS stat & $p$ values \\
\hline $\mathrm{CCO}_{2}$ & -0.4154 & 0.8963 & $-4.3225^{*}$ & 0.0015 & -1.230 & 0.735 & $-4.169^{*}$ & 0.002 \\
\hline GDP & -0.0958 & 0.9247 & $-4.1227 *$ & 0.0027 & -0.806 & 0.858 & $-2.960 * *$ & 0.052 \\
\hline REN & -1.6674 & 0.4392 & $-5.9644 *$ & 0.0000 & -2.199 & 0.244 & $-2.697 * * *$ & 0.093 \\
\hline TI & -1.3173 & 0.6116 & $-6.1135^{*}$ & 0.0000 & -1.210 & 0.752 & $-3.904 *$ & 0.005 \\
\hline
\end{tabular}

Note: *,**, and *** refer $1 \%, 5 \%$, and $10 \%$ level of significance

structural breaks in the series. The study utilized the Zivot and Andrews (ZA) method proposed by Zivot and Andrews (2002) to solve this problem. The advantage of the ZA unit root test is that it can capture stationarity features and a single break in the series. The ZA test outcomes are portrayed in Table 4, which clearly indicate that the series are not stationary at level. However, after the first difference is taken, the series are stationary with $\mathrm{CCO}_{2}$ emissions, economic growth, renewable energy, and technological innovation having structural breaks in 2011, 2001, 2000, and 2011, respectively. The break of 2011 in consumption-based carbon emissions is incorporated while checking the cointegration and long-run results. This break coincides with a series of student-led protests across Chile - known as the Chilean Winter or the Chilean Education Conflict - that demanded a new framework for education in the country, including more direct state participation in secondary education and an end to the existence of profit in higher education (Angell and Pollack, 2014). Hence, political uncertainty and related issues can affect macroeconomic indicators and consumption-based carbon emissions, resulting in a break-in consumption-based carbon emissions (Table 5).

After the series stationarity property is confirmed, the current study investigates the long-run interaction among the parameters. To do this, the study utilized the linear and nonlinear bounds test. The results of the ARDL and NARDL

Table 5 ZA unit root test

\begin{tabular}{|c|c|c|c|c|}
\hline \multirow[b]{2}{*}{ Variables } & \multicolumn{2}{|l|}{ Level } & \multicolumn{2}{|l|}{ Difference } \\
\hline & $t$-stat & $\begin{array}{l}\text { Break- } \\
\text { year }\end{array}$ & $t$-stat & $\begin{array}{l}\text { Break- } \\
\text { year }\end{array}$ \\
\hline $\mathrm{CCO}_{2}$ & -4.1594 & 2001 & $-6.1824 *$ & 2011 \\
\hline GDP & -3.7471 & 2012 & $-4.9262 * * *$ & 2001 \\
\hline REN & -4.8174 & 2010 & $-6.4442 *$ & 2000 \\
\hline $\mathrm{TI}$ & $-5.4373 * *$ & 2009 & $-6.8565^{*}$ & 2011 \\
\hline
\end{tabular}

Note: Critical values: $10 \%, 5 \%$, and $1 \%$ level of significance is depicted by $* * *, * *$, and * respectively bounds tests are depicted in Table 6 . The results of the ARDL bounds test show no evidence of cointegration in the long run, while the NARDL bounds test reveals evidence of cointegration among the variables in the long run. Since there is no cointegration among the series as revealed by the ARDL bounds test, the ARDL long-run estimations cannot be carried out. On the other hand, the results of the NARDL bounds test indicate that we can estimate the long-run results using the NARDL.

The current study utilizes the NARDL after the prerequisite conditions are met. The outcomes of the long-run NARDL are depicted in Table 7. The empirical findings from the NARDL reveal that a positive increase in economic growth harms the quality of the environment. This implies that keeping other indicators constant, a $1 \%$ increase in GDP increases environmental degradation by $2.103 \%$. Also, a reduction in economic growth deteriorates the quality of the environment. Thus, a $1 \%$ decrease in economic growth would increase environmental degradation by $3.283 \%$ when other parameters are held constant.

The long-run outcomes suggest that increases and decreases in economic growth increase environmental degradation in Chile. The study's estimated findings differ from prior studies in terms of the asymmetric effects of shifts in

Table 6 ARDL and NARDL cointegration

\begin{tabular}{llll}
\hline \multicolumn{1}{l}{ Models estimated } & $F$-statistics & Break-year & AIC Lags \\
\hline$\left(\mathrm{CCO}_{2} / \mathrm{GDP}, \mathrm{REN}, \mathrm{TI}\right)$ & 1.6416 & 2011 & {$[1,1,1,0]$} \\
$\left(\mathrm{CCO}_{2} / \mathrm{GDP}^{+}, \mathrm{GDP}^{-}, \mathrm{REN}^{+}\right.$, & $6.2017^{*}$ & 2011 & {$[1,0,0,0,1,1,0]$} \\
$\left.\mathrm{REN}^{-}, \mathrm{TI}^{+}, \mathrm{TI}^{-}\right)$ & & & \\
Model 2 Robustness tests \\
\multicolumn{5}{r}{$F$-stat. } & $p$ value \\
$\chi^{2} \mathrm{LM}$ & 0.807 & 0.457 & \\
$\chi^{2}$ ARCH & 0.112 & 0.739 & \\
$\chi^{2}$ RESET & 2.683 & 0.113 & \\
\hline
\end{tabular}

Note: * refers to a significance level of $1 \%$. Optimum lag length 1 under AIC is used. Robustness tests are not computed for model 1 as there is no cointegration in that 
Table 7 Non-linear ARDL long and short-run results

\begin{tabular}{|c|c|c|c|c|c|c|c|}
\hline \multirow[b]{2}{*}{ Variables } & \multicolumn{3}{|c|}{ Long-run estimation } & \multicolumn{4}{|c|}{ Short-run estimation } \\
\hline & Coefficients & $t$-stat & $p$ value & Variables & Coefficients & $t$-stat & $p$ value \\
\hline $\mathrm{GDP}^{+}$ & $2.103 *$ & 3.9705 & 0.000 & $\mathrm{GDP}^{+}$ & 0.1564 & 0.898 & 0.377 \\
\hline $\mathrm{GDP}^{-}$ & $-3.283^{* *}$ & -2.0995 & 0.045 & $\mathrm{GDP}^{-}$ & $-0.2378 * *$ & -2.250 & 0.033 \\
\hline $\mathrm{REN}^{+}$ & $-0.419 * *$ & -2.4286 & 0.022 & $\mathrm{REN}^{+}$ & -0.1051 & -1.062 & 0.297 \\
\hline $\mathrm{REN}^{-}$ & 0.354 & 1.1977 & 0.241 & $\mathrm{REN}^{-}$ & -0.2114 & -1.215 & 0.235 \\
\hline $\mathrm{TI}^{+}$ & 0.061 & 0.7357 & 0.468 & $T I^{+}$ & $0.1269 * *$ & 2.584 & 0.015 \\
\hline $\mathrm{TI}^{-}$ & $0.160 *$ & 3.3137 & 0.002 & $T \Gamma$ & 0.0165 & 0.819 & 0.420 \\
\hline $\mathrm{DY}^{\mathrm{a}}$ & 0.005 & 0.0847 & 0.933 & DY & 0.0683 & 1.256 & 0.220 \\
\hline $\mathrm{C}$ & $2.377 *$ & 7.7934 & 0.000 & $\mathrm{ECT}(-)$ & $-0.3323 *$ & -5.485 & 0.000 \\
\hline \multicolumn{8}{|l|}{ Diagnostic tests } \\
\hline$R^{2}$ & 0.99 & & & & & & \\
\hline $\operatorname{Adj} R^{2}$ & 0.99 & & & & & & \\
\hline DW statistics & 2.28 & & & & & & \\
\hline$F$-statistics & $625.7[0.000]$ & & & & & & \\
\hline J-B normality & 0.009 [0.995] & & & & & & \\
\hline$\chi^{2} \mathrm{LM}$ & $0.807[0.457]$ & & & & & & \\
\hline$\chi^{2 \mathrm{ARCH}}$ & 0.112 [0.739] & & & & & & \\
\hline$\chi^{2}$ RESET & $2.683[0.113]$ & & & & & & \\
\hline
\end{tabular}

Note: $*$, and $* *$ mirror $1 \%$ and $5 \%$ level of significance. ${ }^{a} \mathrm{DY}$ is a dummy variable included for a break in $\mathrm{CCO}_{2}$ economic growth on environmental degradation. For instance, using data from the USA, the study of Eng and Wong (2015) revealed that $\mathrm{CO}_{2}$ emissions increased from 3 to $4 \%$ between June 1980 and April 1981 due to economic expansion. They further estimated a reduction of 1.37 to $11.37 \%$ in $\mathrm{CO}_{2}$ emissions from the contractionary cycles accompanying these economic expansions. Although our findings of asymmetries largely support Doda (2013), they still differ from the recent asymmetric evidence of business cycles and $\mathrm{CO} 2$ emissions proposed by recent studies. While our observations of asymmetry broadly endorse the studies of Doda (2014) and Baloch et al. (2020), they contradict the findings of prior studies (Burke et al. 2015; Sheldon 2017; York 2012). As revealed by York (2012), economic expansion increases environmental degradation while a reduction in environmental degradation caused by anis economic slowdown.

Nevertheless, York (2012) proposed that $\mathrm{CO}_{2}$ emissions have a symmetric reaction to economic change. Conversely, the present research challenges conventional assertions by investigating whether economic contractions are never subject to pollution over time. While the present study findings contradict York (2012), we still agree with him the sense that $\mathrm{CO}_{2}$ emissions are largely dependent on the nation's economic infrastructure and structure. Therefore, the developed infrastructure (roads, cars, and factories) will still be in operation even when there is a dip in the economy. Additionally, when economic activities reduce, the investment in environmentally friendly activities can reduce. During economic crises, the government may find it difficult to concentrate on environmental sustainability, and businesses may also shift to using cheap pollutant fossil fuels rather than renewables. This can lead to more pollution since the environmentally friendly effects of economic growth subsidize; hence, a reduction in economic growth has a more severe effect on environmental quality than a rise in income. This finding suggests that reductions in economic growth are more detrimental in developing nations like Chile that have enjoyed substantial development in recent decades. Authorities in Chile should consider this outcome when designing environmental and growth strategies, and should focus on economic stability and the transition towards green energy for accomplishing sustainable development and environmental sustainability.

Furthermore, only an increase in renewable energy reduces environmental degradation. Thus, a $0.41 \%$ decrease in environmental degradation will result from a $1 \%$ positive increase in renewable energy usage. This outcome does not comply with the research of Apergis and Payne (2010) for 19 advanced and emerging nations and Menyah and WoldeRufael (2010) for the USA, who established a positive interconnection between renewable energy usage and environmental degradation. The present study's outcome complies with prior studies, such as Kirikkaleli and Adebayo 2020; Shafiei and Salim 2014; Wang et al. 2021a; and Khan et al. 2020a, b, $\mathrm{c}$, who established that an increase in renewable energy helps to mitigate environmental degradation. The probable cause of the negative association is that renewable technology utilizes 
pure and cleaner energy sources that are safe and satisfy current and future necessities, whereas it is also a source of pollution mitigation. This outcome is reasonable in Chile's context since the country has introduced numerous strategies to increase renewable energy consumption and reduce pollutant fossil fuels, including the adoption of the carbon text, shifting electricity production towards renewables, and reducing coalbased electricity consumption. Furthermore, Chile has launched a strategy of electro-mobility, which involves a move towards electricity-based transportation (Carbon Action Tracker, 2020). Our findings indicate that these strategies are quite useful, and increasing renewable energy consumption in Chile mitigates $\mathrm{CCO}_{2}$ emissions.

Moreover, a positive change in technological innovation exerts a positive and insignificant influence on the quality of the environment. Surprisingly, a 1\% reduction in technological innovation decreases environmental degradation by $0.160 \%$. The probable reason for this association is that Chile is not investing in green technology. Thus, a reduction in such technology will enhance the quality of the environment. This is a worrying sign for Chile, and its policymakers should focus on green technology in their innovation strategies. Currently, innovation is ineffective in reducing $\mathrm{CCO}_{2}$ emissions, indicating that it is mostly directed to areas other than environmentally friendly technology.

As anticipated, the ECT is $(-0.33)$, which validates cointegration and defines the speed of adjustment. Table 6 also illustrates the outcomes of the post-estimation tests. The findings show no heteroscedasticity or serial correlation in the model, with the Ramsey test depicting no misspecification in the model. Furthermore, the J-B reveals normal distribution. Moreover, the model is stable as revealed by the CUSUM and CUSUMSQ in Figs. 2 and 3, respectively. The paper's focus is on the long-run estimation, but short-run outcomes are also given in Table 6. Most variables are not significant in the

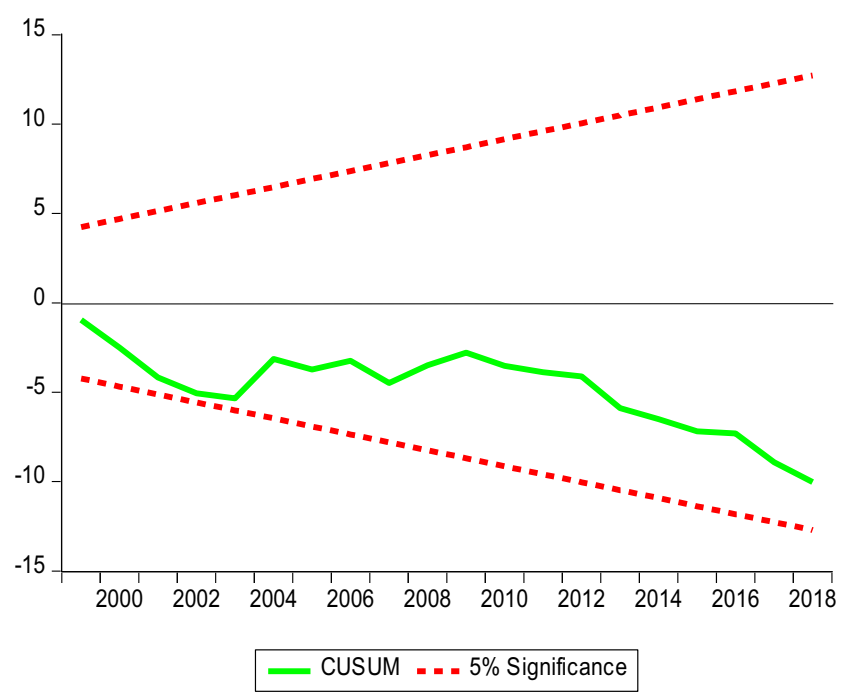

Fig. 2 CUSUM

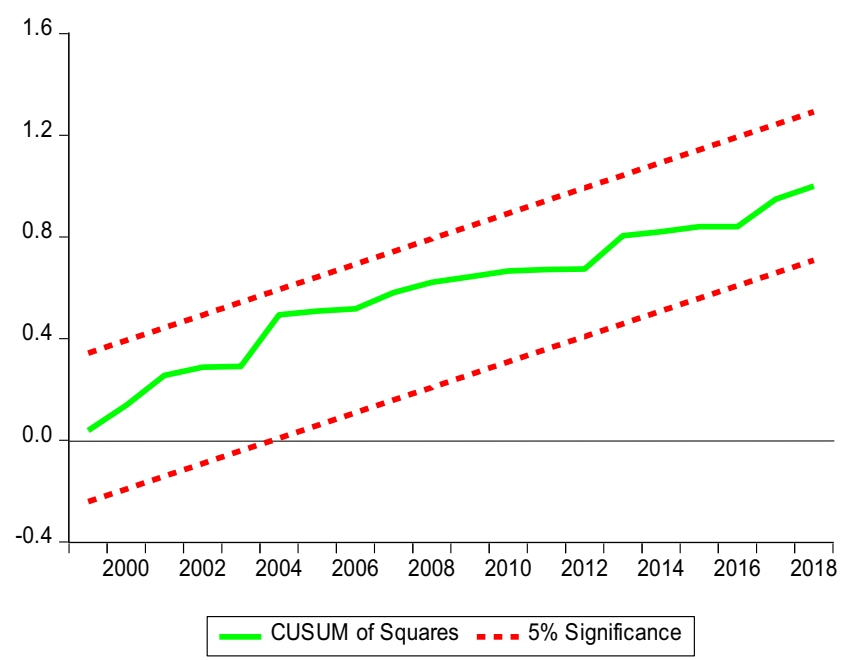

Fig. 3 CUSUMSQ

short-run, except negative GDP, which has similar results to the long run. Technological innovation increases $\mathrm{CCO}_{2}$ emissions in the short run, implying that Chile's innovation is not focused on environmental sustainability, as discussed in the long-run results. However, convergence to the long-run equilibrium takes about 3 years, so differences in short-run shocks are corrected in almost 3 years.

The present paper utilized the Wald test to ascertain the long-run asymmetries' significance. The outcomes of the WALD test are depicted in Table 8. The findings show that both economic growth and renewable energy usage have long-run asymmetries, while technological innovation does not have long-run asymmetries

In order to capture the causal linkage among the variables, the current study utilized an asymmetric causality test. The outcomes of the causality test are portrayed in Table 9. The empirical findings show that positive renewable energy usage Granger causes positive consumption-based carbon emissions. This illustrates that positive renewable energy usage can predict significant variations in positive consumptionbased carbon emissions. Also, a negative shock in technological innovation Granger causes a negative change in consumption-based carbon emissions. This implies that a negative shock in technological innovation can predict the significant variation in positive consumption-based carbon emissions. This outcome suggests that a negative shock in technological innovation can predict a negative shock in

Table 8 Long-run asymmetries (WALD test)

\begin{tabular}{ll}
\hline Variables & $F$-stat $[p$ value $]$ \\
\hline GDP & $19.5374 *[0.0002]$ \\
REN & $11.9595 *[0.0019]$ \\
TI & $1.8399[0.1866]$ \\
\hline
\end{tabular}

Note: $*$ indicates $1 \%$ significance level 
Table 9 Asymmetric causality test

\begin{tabular}{|c|c|c|c|c|}
\hline Path of causality & W.stat & CV (1\%) & $\mathrm{CV}(5 \%)$ & CV $(10 \%)$ \\
\hline $\mathrm{GDP}^{+} \rightarrow \mathrm{CCO}_{2}^{+}$ & 1.858 & 12.031 & 7.317 & 4.902 \\
\hline $\mathrm{GDP}^{-} \rightarrow \mathrm{CCO}_{2}^{-}$ & 0.703 & 7.431 & 4.580 & 2.965 \\
\hline $\mathrm{CCO}_{2}^{+} \rightarrow \mathrm{GDP}^{+}$ & 0.385 & 11.244 & 5.083 & 3.296 \\
\hline $\mathrm{CCO}_{2}^{-} \rightarrow \mathrm{GDP}^{-}$ & 0.003 & 20.467 & 4.443 & 2.387 \\
\hline $\mathrm{REN}^{+} \rightarrow \mathrm{CCO}_{2}^{+}$ & $3.718 * * *$ & 14.150 & 5.582 & 3.453 \\
\hline $\mathrm{REN}^{-} \rightarrow \mathrm{CCO}_{2}^{-}$ & 0.682 & 12.724 & 5.034 & 3.220 \\
\hline $\mathrm{CCO}_{2}^{+} \rightarrow \mathrm{REN}^{+}$ & 0.273 & 10.859 & 5.068 & 3.275 \\
\hline $\mathrm{CCO}_{2}^{-} \rightarrow \mathrm{REN}^{-}$ & 0.002 & 8.716 & 4.071 & 2.850 \\
\hline $\mathrm{TI}^{+} \rightarrow \mathrm{CCO}_{2}^{+}$ & 0.250 & 10.337 & 5.308 & 3.246 \\
\hline $\mathrm{TI}^{-} \rightarrow \mathrm{CCO}_{2}^{-}$ & $11.292 *$ & 9.238 & 4.922 & 3.360 \\
\hline $\mathrm{CCO}_{2}^{+} \rightarrow \mathrm{TI}^{+}$ & 0.068 & 13.827 & 5.559 & 3.979 \\
\hline $\mathrm{CCO}_{2}^{-} \rightarrow \mathrm{T \Gamma}$ & 1.114 & 9.420 & 4.535 & 3.051 \\
\hline $\mathrm{GDP}^{+} \rightarrow \mathrm{REN}^{+}$ & 0.985 & 9.371 & 4.772 & 3.270 \\
\hline $\mathrm{GDP}^{-} \rightarrow \mathrm{REN}^{-}$ & 0.079 & 13.856 & 4.873 & 2.198 \\
\hline $\mathrm{REN}^{+} \rightarrow \mathrm{GDP}^{+}$ & 0.652 & 10.854 & 5.046 & 3.233 \\
\hline $\mathrm{REN}^{-} \rightarrow \mathrm{GDP}^{-}$ & 0.862 & 10.637 & 4.461 & 2.485 \\
\hline $\mathrm{GDP}^{+} \rightarrow \mathrm{TI}^{+}$ & 0.216 & 10.890 & 5.112 & 3.400 \\
\hline $\mathrm{GDP}^{-} \rightarrow \mathrm{TI}^{-}$ & $6.065 * *$ & 44.598 & 5.436 & 3.251 \\
\hline $\mathrm{TI}^{+} \rightarrow \mathrm{GDP}^{+}$ & 0.422 & 9.022 & 4.893 & 3.132 \\
\hline $\mathrm{TI}^{-} \rightarrow \mathrm{GDP}^{-}$ & 0.007 & 103.345 & 3.792 & 1.888 \\
\hline $\mathrm{TI}^{+} \rightarrow \mathrm{REN}^{+}$ & 0.003 & 11.711 & 5.309 & 3.509 \\
\hline $\mathrm{TI}^{-} \rightarrow \mathrm{REN}^{-}$ & 0.157 & 9.016 & 5.192 & 2.963 \\
\hline $\mathrm{REN}^{+} \rightarrow \mathrm{TI}^{+}$ & 2.233 & 11.746 & 4.876 & 3.091 \\
\hline $\mathrm{REN}^{-} \rightarrow \mathrm{TI}^{-}$ & 0.002 & 14.649 & 5.361 & 3.252 \\
\hline
\end{tabular}

Note: Significance level of $1 \%, 5 \%$, and $10 \%$ is depicted $*, * *$, and $* * *$

consumption-based carbon emissions. Lastly, there is an asymmetric causality from negative economic growth to negative technological innovation, which signifies that at a 5\%

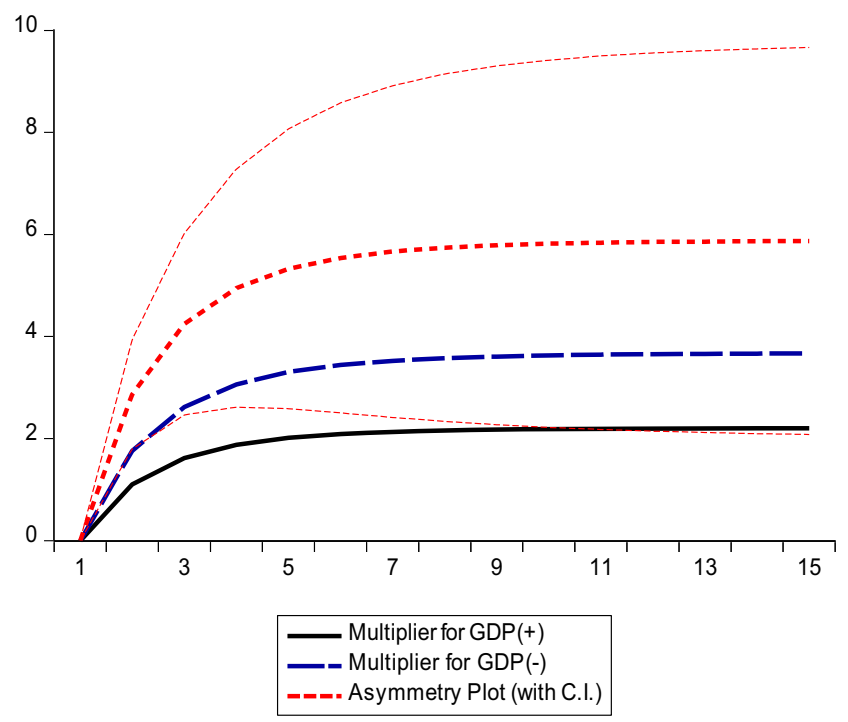

Fig. 4 Multiplier for GDP level of significance, a negative economic growth shock can predict negative technological innovation.

Lastly, Figs. 4, 5, and 6 illustrate the multipliers for the three independent parameters, which illustrate a convergence to an equilibrium after early positive and negative shocks. The non-linear modification of $\mathrm{CCO}_{2}$ emissions to negative

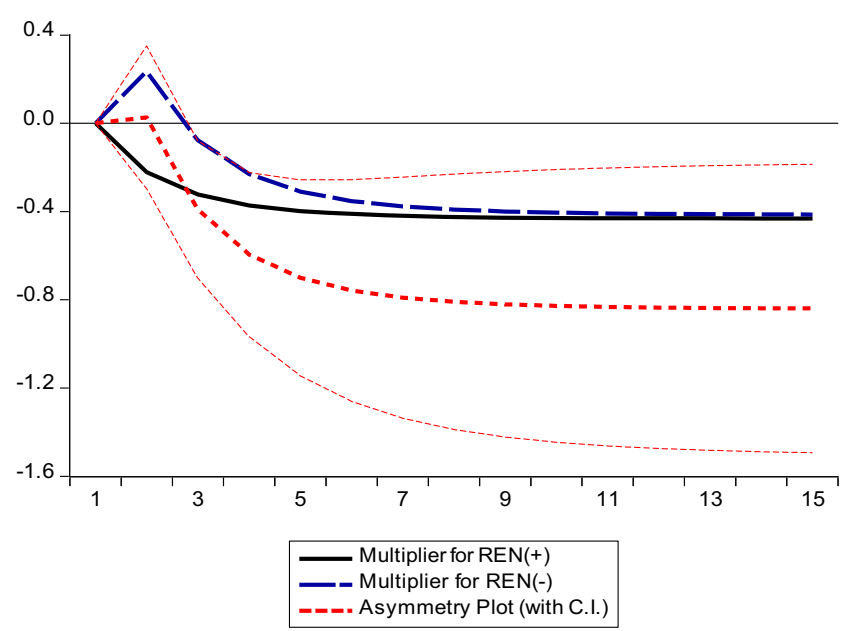

Fig. 5 Multiplier for REN 


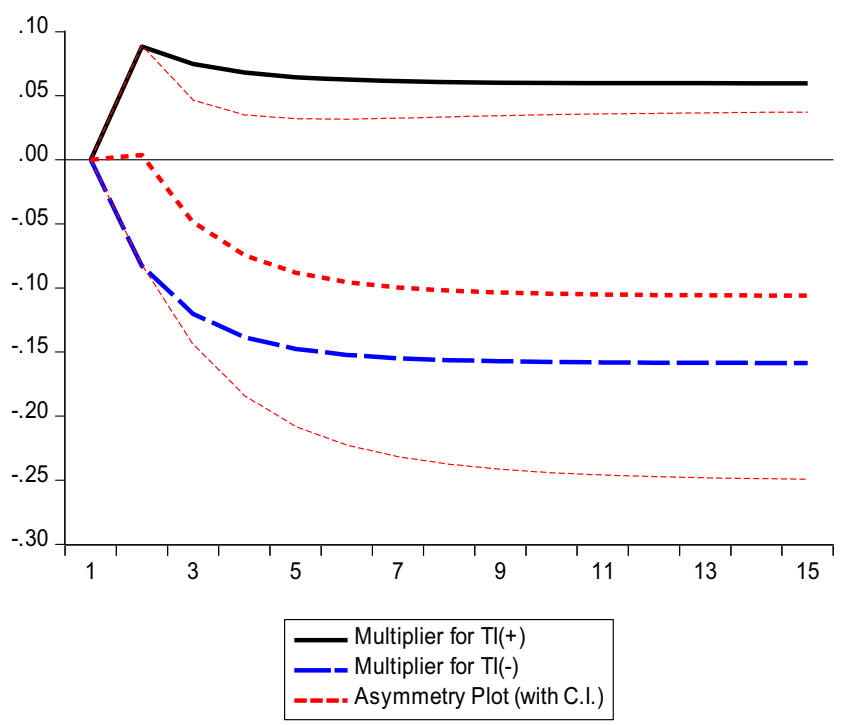

Fig. 6 Multiplier for TI

shocks is depicted by the black dotted line, whereas the solid black line depicts the adjustment of $\mathrm{CCO} 2$ to a positive shock. The red dotted line, which is the asymmetric pattern, is the variation between positive and negative shocks. The outcome in Fig. 1 illustrates that an increase in economic growth has a positive effect on $\mathrm{CCO}_{2}$ emissions, as revealed by the black line, whereas a decrease in economic growth has a positive impact on $\mathrm{CCO}_{2}$ emissions, as revealed by the blue line. Figure 2 reveals that an upsurge in renewable energy consumption has a positive impact on $\mathrm{CCO}_{2}$ emissions, as revealed by the black line, whereas a decrease in renewable energy consumption has a positive effect on $\mathrm{CCO}_{2}$ emissions, as revealed by the blue line. Moreover, the outcomes reveal that the effect of a positive change is more than a negative change. Figure 3 shows that an upsurge in technological innovation exerts a positive impact on $\mathrm{CCO}_{2}$ emissions, as revealed by the black line, whereas a decrease in technological innovation has a negative effect on $\mathrm{CCO}_{2}$ emissions, as revealed by the blue line.

\section{Conclusion and policy direction}

Utilizing Chile, the 5th biggest economy in Latin America, as a case study, the current study examines whether consumption-based carbon emissions $\left(\mathrm{CCO}_{2}\right)$ are nonlinearly influenced by renewable energy usage (REN), technological innovation (TI), and economic growth (GDP) using data from the period from 1990 to 2018. The study employed both linear and non-linear ARDL approaches to investigate these dynamics. Furthermore, the asymmetric causality test was utilized to examine the causal association among the economic variables. The ARDL bounds test outcomes revealed no linear cointegration, while the NARDL bounds test showed evidence of cointegration among the indicators. The NARDL technique's novelty is that it can capture the regressors' positive and negative impacts on $\mathrm{CCO}_{2}$ emissions. Furthermore, the current study included a dummy variable for discontinuity of series to compute the $\mathrm{CCO}_{2}$ function. The outcomes of the unit root test implemented revealed that the series were integrated at first difference. Moreover, the outcomes of the Wald test indicated that the NARDL was suitable for this empirical analysis. The current study outcomes can be utilized for suggesting a policy framework towards the attainment of the SDGs objectives.

The NARDL model outcomes revealed a long-run interconnection between $\mathrm{CCO}_{2}$ emissions, technological innovation, and renewable energy consumption in Chile. In the long run, an increase and decrease in GDP positively impact $\mathrm{CCO}_{2}$, where the impact of the negative change is dominant. Furthermore, an increase in renewable energy consumption is accompanied by a reduction in $\mathrm{CCO}_{2}$ emissions. Moreover, an upsurge in technological innovation exerts an insignificant effect on $\mathrm{CCO}_{2}$ emissions, while a decrease in technological innovation decreases $\mathrm{CCO}_{2}$ emissions. In the short run, a decrease in GDP exerts a positive impact on $\mathrm{CCO}_{2}$ emissions and an increase in technological innovation harms the quality of the environment in Chile. The outcomes of the asymmetric causality revealed that (a) positive renewable energy Granger causes positive $\mathrm{CCO}_{2}$ emissions; (b) a negative shock in technological innovation Granger causes a negative change in $\mathrm{CCO}_{2}$ emissions; (c) a negative shock in technological innovation Granger cause $\mathrm{CCO}_{2}$ emissions; and (d) negative GDP Granger causes technological innovation.

Since an upsurge in environmental degradation accompanies an increase in economic growth, policymakers in Chile should focus on organizing public awareness drives in favor of renewable goods, while the government should place lower tax rates on businesses that use sustainable technologies in their production. We recommend that public budgets in green energy should be increased to promote renewable energy usage. At the same time, there should be collaboration between the public and private sectors to launch more research and development directed towards efficient and clean technology. Strategies should be designed to finance the green energy sector and projects because currently, the innovation is unsustainable. A negative change in economic growth has a more severe impact on environmental quality, so the government should ensure that economic growth continues using clean energy sources. Also, we advocate the subsidization of investment in the development of renewable energy and the adoption of more carbon taxes on fossil fuels to prevent their use and promote the transition to renewable energy sources.

Furthermore, policymakers should encourage green technology, since innovation is currently not directed towards clean technology, and innovation does not reduce consumption-based emissions. We also recommend the 
adoption of strategies aimed increasing educational institutions' research funding, particularly in green technologies, to boost green innovation. The focus should also be on promoting collaboration between universities and industries. This will help in boosting affordable and efficient technologies according to the needs of the industries. In designing policies that include economic growth, technological innovation, environmental degradation, and renewable energy usage, Chile needs to be more vigilant by taking into consideration the existence of asymmetries in the interaction between these variables.

Also, the government should carefully design policies as the ongoing pandemic has also affected the pattern of energy consumption. For instance, household energy consumption has been boosted, and transportation energy consumption has reduced in Chile. Thus, authorities should also focus on increasing energy-efficient resident electric appliances and more renewable solutions for household sectors at affordable prices. This research has a limitation in that it only incorporated only a few factors to explore the drivers of $\mathrm{CCO}_{2}$ due to the limited period of data. As such, additional research is required to examine the asymmetric interconnection among these economic indicators in developing and advanced economies for a more extended period adding more variables to the model.

Acronyms ADF, Augmented Dickey-Fuller; ARDL, Autoregressive distributed lag; BRICS, Brazil, Russia, India, China, and South Africa; $\mathrm{CCO}_{2}$, Consumption-based carbon emissions; $\mathrm{CO}_{2}$, Carbon dioxide; COP21, UN Climate Change Conference in Paris; DOLS, Dynamic ordinary least square; DUM, Dummy variable; ECM, Error correction model; ECT, Error correction term; EKC, Environmental Kuznets curve; EN, Energy consumption; FMOLS, Fully modified ordinary least squares; $\mathrm{GDP}^{-}$, Decrease in economic growth; $\mathrm{GDP}^{+}$, Increase in economic growth; GDP, Economic growth; GHGs, Greenhouse gas emissions; GMM, Generalized method of moments; IEA, International Energy Agency; OECD, The Organization for Economic Co-operation and Development; PMG-ARDL, Pooled Mean Group Autoregressive Distributed Lag; PP, Phillips-Perron; R\&D, Research and development; $\mathrm{REN}^{-}$, Decrease in renewable energy; $\mathrm{REN}^{+}$, Increase in renewable energy; $\mathrm{TI}^{-}$, Decrease in technological innovation; $\mathrm{TI}^{+}$, Increase in technological innovation; TY, Toda and Yamamoto; UAE, United Arab Emirates; VAR, Vector autoregression; ZA, Zivot \& AndrewsSymbols $\theta$, Coefficient of the regressors; $\rho$, Speed of adjustment; $e_{t}$, Error term; $E C T_{t-1}$, Error correction term; $H_{0}$, Null hypothesis; $H_{a}$, Alternative hypothesis

Author contribution Tomiwa Sunday Adebayo collected data and Zahoor Ahmed analyzed it. The introduction and literature review sections are written by Tomiwa Sunday Adebayo and Edmund Ntom Udemba. Tomiwa Sunday Adebayo, Dervis Kirikkaleli and Edmund Ntom Udemba constructed the methodology section and empirical outcomes in the study. Tomiwa Sunday Adebayo and Zahoor Ahmed contributed to the interpretation of the outcomes and policymaking. All the authors read and approved the final manuscript.

Data availability Data is readily available at https://data.worldbank.org/ country/chile

\section{Declarations}

Ethics approval This study follows all ethical practices during writing.

Consent to participate Not applicable

Consent for publication Not applicable

Competing interests The authors declare no competing interests.

\section{References}

Adebayo TS (2020) Revisiting the EKC hypothesis in an emerging market: an application of ARDL-based bounds and wavelet coherence approaches. SN Appl Sci 2(12):1-15

Adebayo TS (2021) Do CO 2 emissions, energy consumption and globalization promote economic growth? Empirical evidence from Japan. Environ Sci Pollut Res:1-16

Adebayo TS, Kirikkaleli D (2021) Impact of renewable energy consumption, globalization, and technological innovation on environmental degradation in Japan: application of wavelet tools. Environ Dev Sustain 4(2):1-26

Adedoyin FF, Bekun FV, Driha OM, Balsalobre-Lorente D (2020) The effects of air transportation, energy, ICT and FDI on economic growth in the industry 4.0 era: Evidence from the United States. Technol Forecast Soc Chang 160:120297

Afionis S, Sakai M, Scott K, Barrett J, Gouldson A (2017) Consumptionbased carbon accounting: does it have a future? Wiley Interdiscip Rev Clim Chang 8(1):e438

Ahmed Z, Le HP (2021) Linking Information Communication Technology, trade globalization index, and CO 2 emissions: evidence from advanced panel techniques. Environ Sci Pollut Res 28(7):8770-8781

Ahmed Z, Zafar MW, Mansoor S (2020a) Analyzing the linkage between military spending, economic growth, and ecological footprint in Pakistan: evidence from cointegration and bootstrap causality. Environ Sci Pollut Res 27(33):41551-41567

Ahmed Z, Nathaniel SP, Shahbaz M (2020b) The criticality of information and communication technology and human capital in environmental sustainability: evidence from Latin American and Caribbean countries. J Clean Prod 286:125529

Ahmed Z, Ali S, Saud S, Shahzad SJH (2020c) Transport CO 2 emissions, drivers, and mitigation: an empirical investigation in India. Air Qual Atmos Health 13(11):1367-1374

Ahmed Z, Cary M, Le HP (2021) Accounting asymmetries in the longrun nexus between globalization and environmental sustainability in the United States: an aggregated and disaggregated investigation. Environ Impact Assess Rev 86:106511. https://doi.org/10.1016/j. eiar.2020.106511

Akinsola GD, Adebayo TS (2021) Investigating the causal linkage among economic growth, energy consumption, and $\mathrm{CO} 2$ emissions in Thailand: an application of the wavelet coherence approach. Int J Renew Energy Dev 10(1):17-26

Alola AA (2019) The trilemma of trade, monetary and immigration policies in the United States: accounting for environmental sustainability. Sci Total Environ 658:260-267

Alola AA, Kirikkaleli D (2020) Global evidence of time-frequency dependency of temperature and environmental quality from a wavelet coherence approach. Air Qual Atmos Health 2(4):1-9

Alola AA, Lasisi TT, Eluwole KK, Alola UV (2020) Pollutant emission effect of tourism, real income, energy utilization, and urbanization in 
OECD countries: a panel quantile approach. Environ Sci Pollut Res 4(6): $1-10$

Álvarez-Herránz A, Balsalobre D, Cantos JM, Shahbaz M (2017) Energy innovations-GHG emissions nexus: fresh empirical evidence from OECD countries. Energy Policy 101:90-100

Angell A, Pollack B (2014) The Chilean Elections of 1989 and the Politics of the Transition to Democracy. Bull Lat Am Res 9(1):1-23

Apergis N, Ozturk I (2015) Testing environmental Kuznets curve hypothesis in Asian countries. Ecol Indic 52:16-22

Apergis N, Payne JE (2010) Renewable energy consumption and economic growth: evidence from a panel of OECD countries. Energy Policy 38(1):656-660

Ayobamiji AA, Kalmaz DB (2020) Reinvestigating the determinants of environmental degradation in Nigeria. Int $\mathrm{J}$ Econ Policy Emerg Econ 13(1):52-71

Baloch A, Shah SZ, Habibullah MS, Rasheed B (2020) Towards connecting carbon emissions with asymmetric changes in economic growth: evidence from linear and non-linear ARDL approaches. Environ Sci Pollut Res 2(1):1-19

Balsalobre-Lorente D, Leitão NC (2020) The role of tourism, trade, renewable energy use and carbon dioxide emissions on economic growth: evidence of tourism-led growth hypothesis in EU-28. Environ Sci Pollut Res 27(36):45883-45896

Barrett J, Peters G, Wiedmann T, Scott K, Lenzen M, Roelich K, le Quéré C (2013) Consumption-based GHG emission accounting: a UK case study. Clim Pol 13:451-470

Bhattacharya M, Paramati SR, Ozturk I, Bhattacharya S (2016) The effect of renewable energy consumption on economic growth: evidence from top 38 countries. Appl Energy 162:733-741

Bhattacharya M, Inekwe JN, Sadorsky P (2020) Consumption-based and territory-based carbon emissions intensity: determinants and forecasting using club convergence across countries. Energy Econ 86: 104632

BP Statistical Review of World Energy (2020) https://www.bp.com/ content/dam/bp/business-sites/en/global/corporate/pdfs/ energyeconomics/statistical-review/bp-stats-review-2020-fullreport.pdf. Accessed March 2021

Brizga J, Feng K, Hubacek K (2017) Household carbon footprints in the Baltic States: a global multi-regional input-output analysis from 1995 to 2011. Appl Energy 189:780-788

Broock WA, Scheinkman JA, Dechert WD, LeBaron B (1996) A test for independence based on the correlation dimension. Econom Rev 15(3):197-235

Burke M, Hsiang SM, Miguel E (2015) Global non-linear effect of temperature on economic production. Nature 527(7577):235-239

Cai B, Zhou L (2014) Urban CO2 emissions in China: spatial boundary and performance comparison. Energy Policy 66:557-567

Chiu CL, Chang TH (2009) What proportion of renewable energy supplies is needed to initially mitigate CO2 emissions in OECD member countries? Renew Sust Energ Rev 13(6-7):1669-1674

Chiu CM, Chang CC, Cheng HL, Fang YH (2009) Determinants of customer repurchase intention in online shopping. Online information review

Dawkins E, Roelich K, Owen A (2010) A consumption approach for emissions accounting-the REAP tool and REAP data for 2006. SEI Project Report 22(1):22-31

Doda B (2013) Emissions-GDP relationship in times of growth and decline (No. 116). Grantham Research Institute on Climate Change and the Environment

Doda B (2014) Evidence on business cycles and CO2 emissions. J Macroecon 40:214-227

Eng YK, Wong CY (2015) Tapered US carbon emissions during good times: what's old, what's new? Environ Sci Pollut Res 24(32): 25047-25060
Feng K, Brizga J, Hubacek K (2013) Drivers of CO2 emissions in the former Soviet Union: A country level IPAT analysis from 1990 to 2010. Energy 59:743-753

Ferng J-J (2003) Allocating the responsibility of CO2 over-emissions from the perspectives of benefit principle and ecological deficit. Ecol Econ 46:121-141

Gessinger G (1997) Lower CO2 emissions through better technology. Energy Convers Manag 38:S25-S30

Gilfillan SM, Frank N, Schroeder-Ritzrau A, Burnside NM, Haszeldine RS (2019) 420,000 year assessment of fault leakage rates shows geological carbon storage is secure. Sci Rep 9(1):1-9

Hasanov FJ, Liddle B, Mikayilov JI (2018) The impact of international trade on $\mathrm{CO} 2$ emissions in oil exporting countries: territory vs consumption emissions accounting. Energy Econ 74:343-350

Hatemi-j A (2012) Asymmetric causality tests with an application. Empir Econ 43(1):447-456

He X, Adebayo TS, Kirikkaleli D, Umar M (2021) Consumption-based carbon emissions in Mexico: An analysis using the dual adjustment approach. Sustain Prod Consum 27:947-957

Huaman RNE, Tian X (2014) Energy related CO2 emissions and the progress on CCS projects: a review. Renew Sustain Energy Rev 31:368-385

Inglesi-Lotz R, Dogan E (2018) The role of renewable versus nonrenewable energy to the level of $\mathrm{CO} 2$ emissions a panel analysis of sub-Saharan Africa's Big 10 electricity generators. Renew Energy 123:36-43

Khan MK, Khan MI, Rehan M (2020) The relationship between energy consumption, economic growth and carbon dioxide emissions in Pakistan. Financial Innovation 6(1):1-13

Khan Z, Ali M, Jinyu L, Shahbaz M, Siqun Y (2020a) Consumptionbased carbon emissions and trade nexus: evidence from nine oil exporting countries. Energy Econ 89:104806

Khan Z, Ali S, Umar M, Kirikkaleli D, Jiao Z (2020b) Consumptionbased carbon emissions and international trade in G7 countries: the role of environmental innovation and renewable energy. Sci Total Environ 730:138945

Khan Z, Ali S, Umar M, Kirikkaleli D, Jiao Z (2020c) Consumptionbased carbon emissions and international trade in G7 countries: the role of environmental innovation and renewable energy. Sci Total Environ 730:138945-138945

Kirikkaleli D, Adebayo TS (2020) Do renewable energy consumption and financial development matter for environmental sustainability?\&nbsp;New global evidence. Sustain Dev 4(12):1-12

Kirikkaleli D, Adebayo TS (2021) Do public-private partnerships in energy and renewable energy consumption matter for consumptionbased carbon dioxide emissions in India? Environ Sci Pollut Res 6(4):1-14

Kirikkaleli D, Adebayo TS, Khan Z, Ali S (2020) Does globalization matter for ecological footprint in Turkey? Evidence from dual adjustment approach. Environ Sci Pollut Res 8(3):1-9

Knight KW, Schor JB (2014) Economic growth and climate change: a cross-national analysis of territorial and consumption-based carbon emissions in high-income countries. Sustainability 6(6):3722-3731

Lee K, Min T (2015) The dynamic links between carbon dioxide (CO2) emissions, health spending and GDP growth: A case study for 51 countries. Environ Res 158:137-144

Liu Z, Guan D, Wei W, Davis SJ, Ciais P, Bai J, Peng S, Zhang Q, Hubacek K, Marland G, Andres RJ, Crawford-Brown D, Lin J, Zhao H, Hong C, Boden TA, Feng K, Peters GP, Xi F, Liu J, Li Y, Zhao Y, Zeng N, He K (2015) Reduced carbon emission estimates from fossil fuel combustion and cement production in China. Nature 524(7565):335-338

Magazzino C, Udemba EN, Bekun F (2020) Modelling the nexus between pollutant emission, energy consumption, foreign direct investment and economic growth: new insights from China. Environ Sci Pollut Res 27:17831-17842 
Mensah CN, Long X, Boamah KB, Bediako IA, Dauda L, Salman M (2018) The effect of innovation on CO 2 emissions of OCED countries from 1990 to 2014. Environ Sci Pollut Res 25(29):2967829698

Menyah K, Wolde-Rufael Y (2010) CO2 emissions, nuclear energy, renewable energy and Eng, Y., \& Wong, C. (2015). Toward a decarbonizing economic expansion: evidence from non-linear Ardl approach. economic growth in the US. Energy Policy 38(6):29112915

Mi ZF, Pan SY, Yu H, Wei YM (2015) Potential impacts of industrial structure on energy consumption and $\mathrm{CO} 2$ emission: a case study of Beijing. J Clean Prod 103:455-462

Munksgaard J, Pade L-L, Minx J, Lenzen M (2005) Influence of trade on national CO2emissions. Int J Glob Energy Issues 23:324-336

Odugbesan JA, Adebayo TS (2020a) Modeling CO 2 emissions in South Africa: empirical evidence from ARDL based bounds and wavelet coherence techniques. Environ Sci Pollut Res 2(7):1-13

Odugbesan JA, Adebayo TS (2020b) The symmetrical and asymmetrical effects of foreign direct investment and financial development on carbon emission: evidence from Nigeria. SN Appl Sci 2(12):1-15

Olanrewaju VO, Adebayo TS, Akinsola GD, Odugbesan JA (2021) Determinants of environmental degradation in Thailand: empirical evidence from ARDL and wavelet coherence approaches. Pollution 7(1):181-196

Oluwajana D, Akinsola GD, Osemeahon OS, Adebayo TS, Kirikkaleli D, Adeshola I (2021) Coal consumption and environmental sustainability in South Africa: The role of financial development and globalization. Int J Renew Energy Dev

Onyibor K, Adebayo TS, Akinsola GD (2020) The impact of major macroeconomic variables on foreign direct investment in Nigeria: evidence from a wavelet coherence technique. SN Business \& Economics 1(1): 1-24

Peters GP, Hertwich EG (2008) CO2 embodied in international trade with implications for global climate policy. Environ Sci Technol 42: $1401-1407$

Peters GP, Aamaas B, Berntsen T, Fuglestvedt JS (2011) The integrated global temperature change potential (iGTP) and relationships between emission metrics. Environ Res Lett 6(4):044021

Safi A, Chen Y, Wahab S, Ali S, Yi X, Imran M (2020) Financial instability and consumption-based carbon emission in E-7 countries: The role of trade and economic growth. Sustain Prod Consum 27:383391

Shafiei S, Salim RA (2014) Non-renewable and renewable energy consumption and $\mathrm{CO} 2$ emissions in OECD countries: a comparative analysis. Energy Policy 66:547-556

Shahbaz M, Zakaria M, Shahzad SJH, Mahalik MK (2018) The energy consumption and economic growth nexus in top ten energyconsuming countries: fresh evidence from using the quantile-onquantile approach. Energy Econ 71:282-301

Shahbaz M, Raghutla C, Chittedi KR, Jiao Z, Vo XV (2020) The effect of renewable energy consumption on economic growth: evidence from the renewable energy country attractive index. Energy 207:118162

Sheau-Ting L, Al-mulali U (2014) Econometric analysis of trade, exports, imports, energy consumption and $\mathrm{CO} 2$ emission in six regions. Renew Sustain Energy Rev 33:484-498

Sheikh AZ, Anser MK, Yousaf Z, Hishan SS, Nassani AA, Vo XV, Abro MMQ (2020) Dynamic linkages between transportation, waste management, and carbon pricing: Evidence from the Arab World. J Clean Prod 2(5):122-134

Sheldon TL (2017) Asymmetric effects of the business cycle on carbon dioxide emissions. Energy Econ 61:289-297
Shin Y, Yu B, Greenwood-Nimmo M (2014) Modelling asymmetric cointegration and dynamic multipliers in a non-linear ARDL framework. In: Festschrift in honor of Peter Schmidt. Springer, New York, NY, pp 281-314

Stern N (2016) Economics: current climate models are grossly misleading. Nature 530(7591):407-409

$\mathrm{Su}$ B, Ang BW (2014) Input-output analysis of CO2 emissions embodied in trade: a multi-region model for China. Appl Energy 114:377-384

Udemba EN (2019) Triangular nexus between foreign direct investment, international tourism, and energy consumption in the Chinese economy: accounting for environmental quality. Environ Sci Pollut Res 26(24):24819-24830

Udemba EN (2020a) A sustainable study of economic growth and development amidst ecological footprint: new insight from Nigerian perspective. Sci Total Environ 7(8):139-140

Udemba EN (2020b) Mediation of foreign direct investment and agriculture towards ecological footprint: a shift from single perspective to a more inclusive perspective for India. Environ Sci Pollut Res 2(7): 26817-26834

Udemba EN (2020c) Ecological implication of offshored economic activities in Turkey: foreign direct investment perspective. Environ Sci Pollut Res 27(30):38015-38028

Udemba EN (2021) Nexus of ecological footprint and foreign direct investment pattern in carbon neutrality: new insight for United Arab Emirates (UAE). Environmental Science and Pollution Research, 1-19

Umar M, Ji X, Kirikkaleli D, Xu Q (2020) COP21 Roadmap: do innovation, financial development, and transportation infrastructure matter for environmental sustainability in China? J Environ Manag 2(7): $111-121$

Wang Z, Bui Q, Zhang B, Nawarathna CLK, Mombeuil C (2021a) The nexus between renewable energy consumption and human development in BRICS countries: the moderating role of public debt. Renew Energy 165:381-390

Wang KH, Liu L, Adebayo TS, Lobon OR, Claudia MN (2021b) Fiscal decentralization, political stability and resources curse hypothesis: A case of fiscal decentralized economies. Resour Policy 72:102071

WDI (2020). World Development Indicator. https://data.worldbank.org/. Accessed 2 April 2021

York R (2012) Asymmetric effects of economic growth and decline on CO 2 emissions. Nat Clim Chang 2(11):762-764

Yu S, Wei Y-M, Fan J, Zhang X, Wang K (2012) Exploring the regional characteristics of inter-provincial $\mathrm{CO} 2$ emissions in China: an improved fuzzy clustering analysis based on particle swarm optimization. Appl Energy 92:552-562

Zhang YJ, Da YB (2015) The decomposition of energy-related carbon emission and its decoupling with economic growth in China. Renew Sust Energ Rev 41:1255-1266

Zhang N, Yu K, Chen Z (2017) How does urbanization affect carbon dioxide emissions? A cross-country panel data analysis. Energy Policy 107:678-687

Zhang L, Li Z, Kirikkaleli D, Adebayo TS, Adeshola I, Akinsola GD (2021) Modeling CO 2 emissions in Malaysia: an application of Maki cointegration and wavelet coherence tests. Environ Sci Pollut Res 8(4):1-15

Zivot E, Andrews DWK (2002) Further evidence on the great crash, the oil-price shock, and the unit-root hypothesis. Journal of Business \& Economic Statistics 20(1):25-44

Publisher's note Springer Nature remains neutral with regard to jurisdictional claims in published maps and institutional affiliations. 